\title{
A Scheduling and Cooperation Mechanism of Simulation Task
}

\author{
G.F. XU, Y.W. CAI, L. CHENG, Z.Y. ZHAO \\ Equipment Academy, Beijing, China
}

\begin{abstract}
A scheduling and cooperation mechanism for simulations with strict rotation is studied in this paper. The mechanism is designed from 2 aspects of scheduling and cooperation. The scheduling is studied based on the idea of project management. And the cooperation is studied and improved based on the basic contract net protocol. The complete process is designed at last. The designed mechanism can provide a certain theories basis and practice guidance for simulations with strict rotation.
\end{abstract}

KEYWORD: Scheduling; Cooperation; Simulation Task; Work Breakdown

\section{INTRODUCTION}

Nowadays, there are more and more Agent based simulations with strict rotation. And the problem is always cannot be completed by a single Agent. In order to ensure the effective implementation of the simulation tasks, which simulation task should be executed and which Agent to execute this simulation task are two key problems to be solved.

According to these two problems, a scheduling and cooperation mechanism is studied. The scheduling mechanism is studied based on the work breakdown of project [1]. And the cooperation mechanism is studied and improved based on the basic contract net protocol [2]. Then a scheduling and cooperation process is designed.

The rest of the paper is organized in the following sequence. In section 2 , the relationship between scheduling and cooperation is introduced in detail. In section 3, the scheduling mechanism is designed. In section 4 , the cooperation mechanism is designed. In section 5, the work process of scheduling and cooperation mechanism is introduced in detail. Concluding remarks are summarized in the final section.

\section{THE RELATIONSHIP BETWEEN SCHEDULING AND COOPERATION}

The specific wok of scheduling and cooperation mechanism and the relationship between them are shown as follows:
1. The foundation of scheduling and cooperation The problems are breaking down as projects. The results are related tasks with one another. And the related tasks are the foundation of scheduling and cooperation.

2. The specific work of scheduling

The specific work of scheduling is scheduling the simulation tasks according to relevance of simulation tasks.

3. The specific work of cooperation

The specific work of cooperation is to find out the best Agent to execute the task according to the task requirements.

The relationship between scheduling and cooperation is shown in Fig. 1.

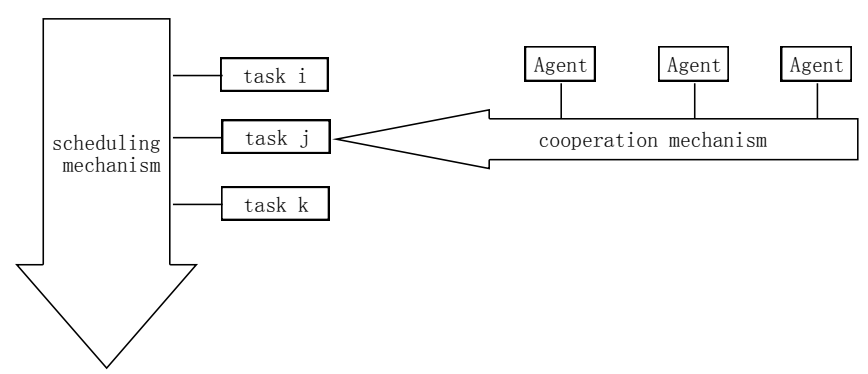

Fig.1. The relationship between scheduling and cooperation

Scheduling makes the simulation model move forward by the work break down as a project. Cooperation is to find out the best executing Agent laterally based on the scheduling. They depend on each other. So, scheduling is the foundation of cooperation, and cooperation is the key of completion of scheduling. 


\section{THE SCHEDULING MECHANISM}

The project is a organized and planed implementation process, which is based on set of specific related tasks and use all kinds resources effectively, in order to achieve a specific goal[3]. The 3 elements of the project are range, time and cost. To solve the problems of reality, the problems should be regards as projects.

The schedule is based on time series. The form of the record of schedule is shown as follows:

$$
\begin{aligned}
& \text { Record }=\left(I D, \text { Task }_{i d}, \text { Agent }_{\text {type }},\right. \\
& \left.\operatorname{Re} q_{\text {time }}, \operatorname{Re} q_{\text {cost }}, \operatorname{Re} q_{\text {quality }}, \text { Link }_{\text {task }}, \text { Link }_{\text {type }}\right)
\end{aligned}
$$

Based on the schedule, the scheduling decision can carry out. The process of scheduling is designed and shown in Fig. 2.

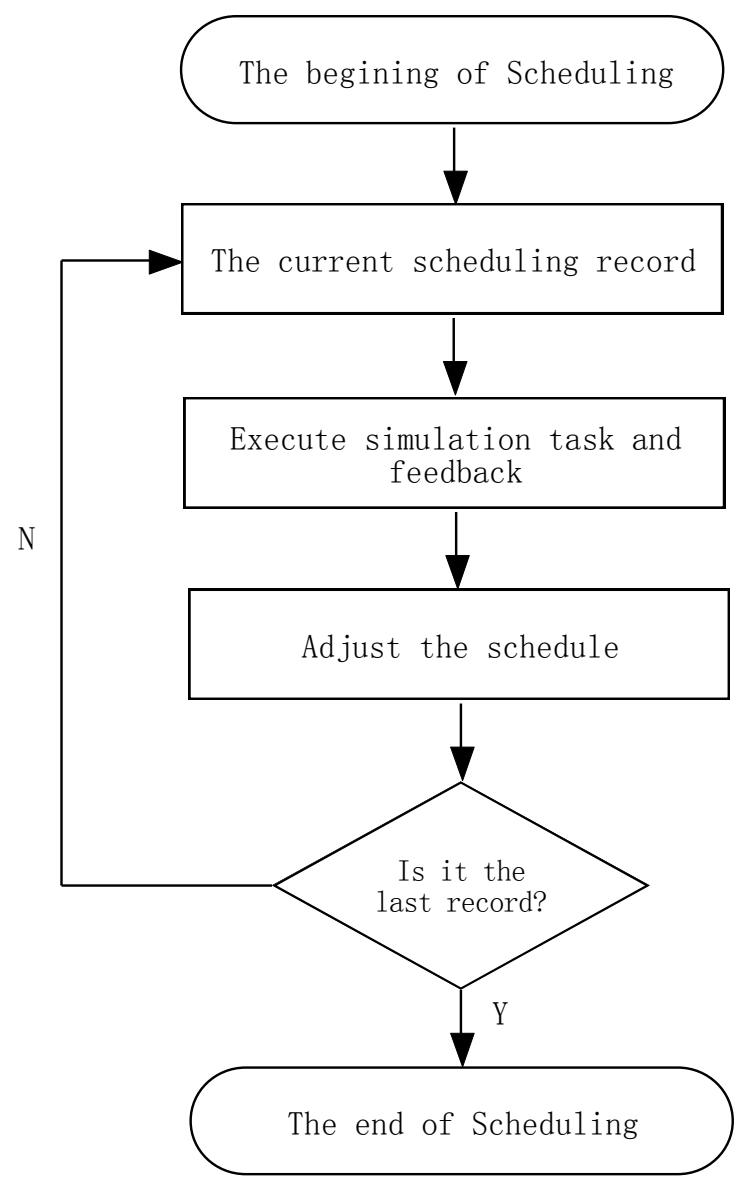

Fig. 2. The process of scheduling

\section{THE COOPERATION MECHANISM}

Contract net protocol is a widely used distributed control structure model when the collaborative problems of complex systems are studied [4]. The work flow of the basic contract net protocol is shown in Fig. 3.

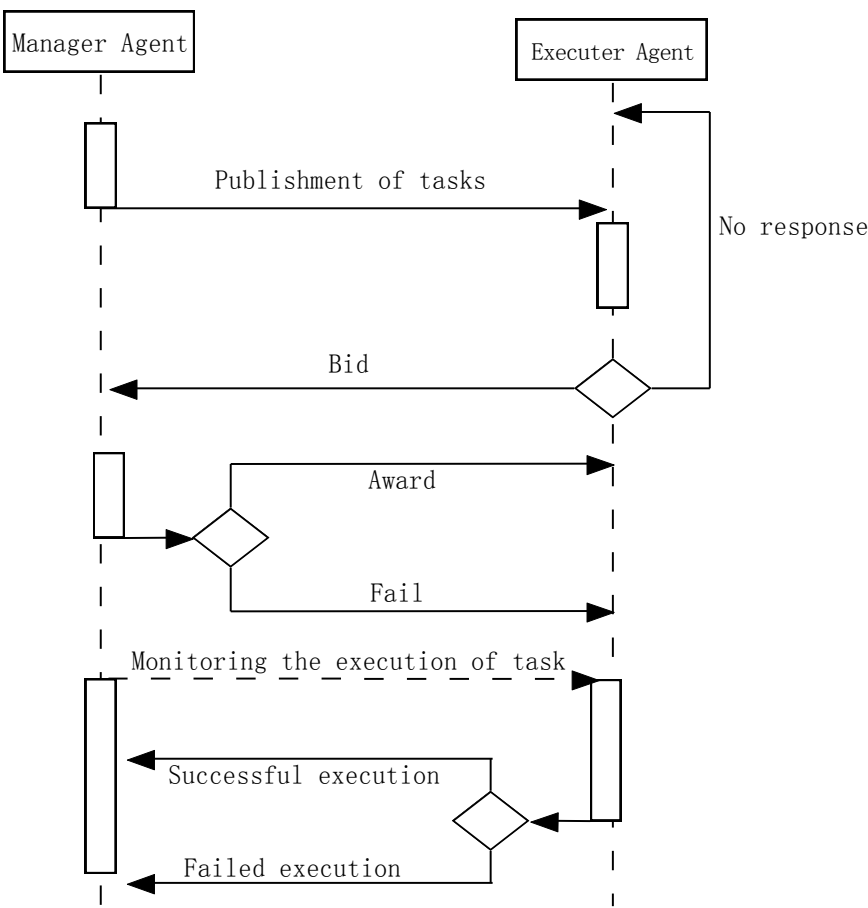

Fig. 3. The work flow of the basic contract net protocol

To improve the execution efficiency and combined with the actual situation, the improvements of the basic contract net protocol are shown as follows:

1. Before bidding, the qualifications of Agent should be examined. And the database should be established too[5].

2. The tender should be designed according to the practical problems.

3. The method of bid evaluation should be redesigned as well.

4. Extend the feedback information of Agent.

\section{THE COMBINATION OF SCHEDULING AND COOPERATION MECHANISM}

After the completion of the design of scheduling mechanism and cooperation mechanism, a complete process is designed and shown in Fig. 4. The work process is as follows:

1. Begin the scheduling according to the scheduling table records.

2. The scheduling decision get out according to the current scheduling information and feedback information, and the new scheduling information get send out.

3. The best Agent would be found out according to the new scheduling information and the result of tender.

4. Agent executes the simulation task and delivery the feedback.

5. If the current scheduling record is the last one, end the scheduling and the simulation model comes to ending too. If not, then go to step 2. 


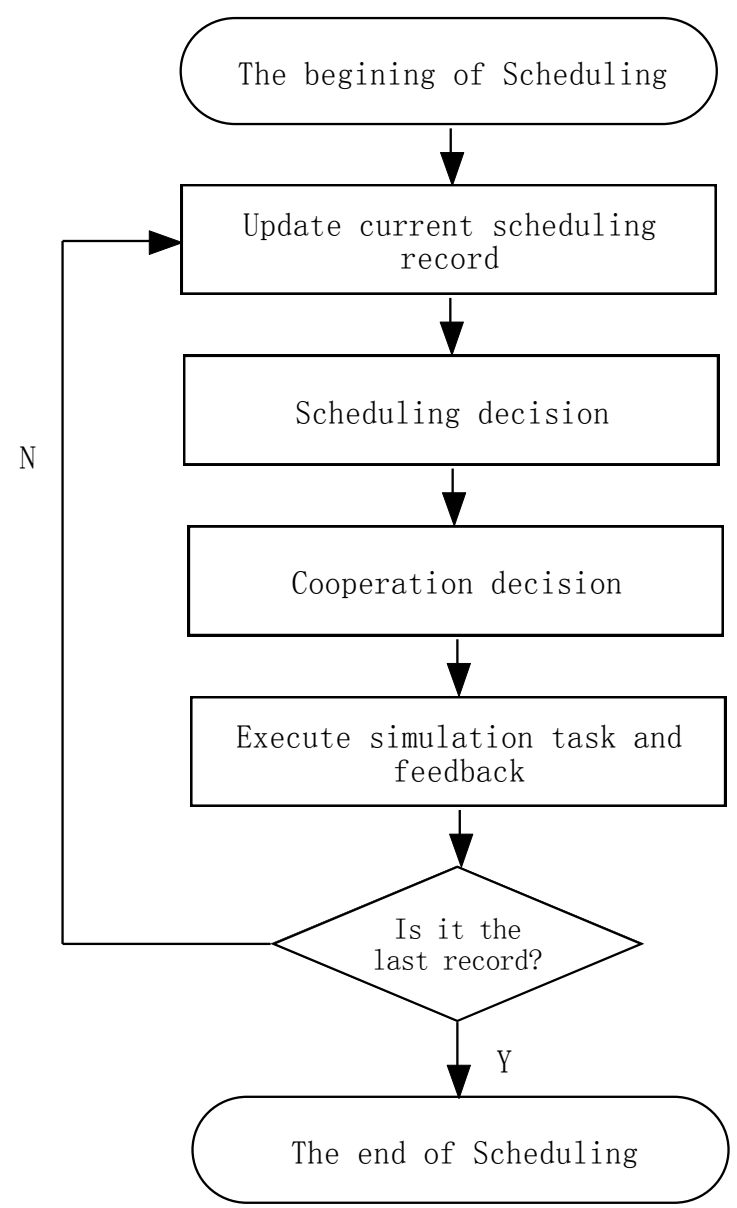

Fig. 4. The work flow of the basic contract net protocol

\section{CONCLUSION}

In this paper, a scheduling and cooperation mechanism for simulations with strict rotation is studied, which is based on the idea of project management and the basic contract net protocol. And a complete work flow is designed. With more and more Agent based modeling and simulations with strict rotation, the thoughts and methods designing the scheduling and cooperation mechanism will get wider and wider application to solve complex problems, such as space launch, equipment acquisition etc.

\section{REFERENCES}

[1] Turner J R. The handbook of project-based management. London: McGraw-Hill, 1999.

[2] Singh A, Juneja D, Sharma A K. Introducing Trust Establishment Protocol in Contract Net Protocol //Advances in Computer Engineering (ACE), 2010 International Conference on. IEEE, 2010: 59-63.

[3] GAO Yi. Course of Project Management. Beijing: Tsinghua university press, 2010.

[4] ZHANG Hai-jun, SHI Dong-zhi. Dynamic Contract Net Protocol. Computer Engineering, 2004, 30(21):44-47.

[5] QU Wei, ZHENG Shao-yu. Introduction to military equipment acquisition. Beijing: The people's Liberation Army press, 2003. 